\title{
The Roles of Enterprise Resource Planning and Management Control on Knowledge Sharing
}

\author{
Izzeideen A. Alomari, Amizawati Mohd Amir, Sofiah Md Auzair \& Khairul Azman Aziz
}

\begin{abstract}
This study signifies knowledge as strategic resources in attaining organisational mission and vision. With the increasing trend of employee turnover, the need to retain knowledge is a challenge, and thus, fostering organisational knowledge sharing is an option to uphold the knowledge. The advancement of the technology, together with management control systems have crucial roles in effectively sharing knowledge. This study aims to examine the relationship between Enterprise Resource Planning (ERP), management control (MC) and their complementarity effect towards facilitating organisational knowledge sharing (KS) practice. Questionnaires were administered to top management of randomly selected manufacturer listed in the Federation of Malaysian Manufacturers Directory. 114 usable responses were analysed using partial least square structural equation modelling (PLS-SEM). The results indicate positive and significant relationships between ERP, MC and KS, hence suggesting the knowledge sharing role of ERP and MC as governing mechanism to KS. The complementarity effect between ERP and MC was also found to be positively associated with $K S$. The results provide evidence on the importance of appropriate governing control mechanism in combination with enhanced technology to foster organizational knowledge-sharing practice.
\end{abstract}

Keywords: Enterprise resource planning; management control; knowledge sharing

\section{INTRODUCTION}

Knowledge is a strategic business resource, and thus, to sustain in the present competitive market, firms need to capitalise and manage their organisational knowledge well. Nevertheless, retaining knowledge is a challenge in today's organisations. Given the increasing number of retiring experienced staff, along with millennials job-jumping trend, knowledge is leaving the firms at a rapid rate (Forbes 25th June 2019). Fostering knowledge sharing environment among the organisational citizens is an option to uphold the knowledge, and essential to all social systems (Anand \& Walsh 2016). Sharing knowledge is essential for organisations to create, capture, share and apply knowledge. Knowledge sharing (KS) captures, organises, reuse, and transfers the knowledge within the organisation boundary, without departmental or geographical restrictions (Mittal \& Dhar 2016). Recognising knowledge, both explicit and tacit, as a success factor in maximising the organisational ability to ensure business sustainability through generating new ideas and developing new business opportunities (Lin 2007; Muthuveloo et al. 2017; Chiu et al. 2018; Ahmed et al. 2021), disregard the importance of nurturing KS may jeopardise firms' long-term survival.

The digitisation technology advancement has a close-linked in maximising KS. Often referred to as KS enabler, the technology allows quick search, access, retrieve and communicate the information within the organisation. The digital technologies have a significant impact on knowledge capital, particularly on how firms create, distribute and use the information (Griffin \& Wright 2015; Presenza et al. 2017). Considering that the required information needs to be comprehensive, precise, valid, accurate, relevant, consistent, and timely, the Enterprise Resource Planning (ERP) system often is a proxy for digitalisation practice (Warren et al. 2015; Bley et al. 2016; Redman 2018). ERP systems qualify as the most crucial development in the business use of IT since the systems integrate into a collaborative platform as many business functions as possible. ERP systems improve the availability of real-time integrated information which is crucial for many firms and can carry out works in the organisation. The technology has profound, far-reaching implications in terms of the scale, accessibility, availability of knowledge and the interactions between firms, people, and knowledge. It also acts as an information system playing a role in overseeing and coordinating all the resources, information and functions of a business from shared data stores. The enterprise systems provide organisation citizens with access to relevant and real-time operational data that facilitate collection and dissemination of organisational knowledge (Appelbaum et al. 2017). Besides converting tacit knowledge into explicit knowledge, the ERP systems also being associated with significant business benefits, among them, are reducing inventory, enable faster information transactions, facilitate better financial management, maintain tightened supply-chain links, and improve responsiveness to customers (Davenport 1998). In other words, ERP can influence not only the business activities but also the people at work (Cleary \& Quinn 
2016). ERP systems claim to create effective KS and subsequently stimulate better business actions (Acar et al. 2017; Jayawickrama et al. 2019). Accordingly, firms invested a considerable amount in setting up their ERP systems, mainly to store and integrate company resources and improving the capability of managers with access to the information to support management decision making as KS among organisational employees is becoming a priority in most organisations (Appelbaum et al. 2017).

However, an individual's willingness to share their knowledge with others is uncertain, as Anand and Walsh (2016) describe as an unnatural act. Consistent with Lin's (2007) findings, technology encourages knowledge collection, but not knowledge donating, implying the employee's tendency to use the knowledge for their advantage instead of building up the organisational resources. Numerous studies (e.g., Lin 2007; Shurafa \& Mohamed 2016; Anand \& Walsh 2016) has put forward the need for a control system to guard against such conflict while inculcating a value to be shared by its members and, in turn, influence their thoughts and actions. Moreover, 66 to 70 per cent of ERP implementation has reported failures (Lengnick-Hall et al. 2004; Žabjek et al. 2009; Tarhini et al. 2016), while 50 to 90 per cent unable to meet the expected return (Amid et al. 2012; Garg \& Garg 2013) suggesting that ERP also cannot stand alone. Without proper control, the system cannot promise a business success. Hsu (2013) state that technology rarely acts alone in creating or sustaining a competitive advantage. Instead, it has to act hand in hand with other resources to establish firms' competitive advantage. Regardless of technology advancement, firms are composed of people with diverse interests that need to be controlled and directed towards specific goals. The study thus observes the roles of ERP and Management Control (MC) on KS.

$\mathrm{MC}$ is a crucial determinant of explaining why some firms are better than others in sharing their knowledge. MC form a significant component of the internal organisational environment, comprises rules, practices, values and other management activities that provide and communicate directions to the organisational employees towards the organisational best interest (Malmi \& Brown 2008; Grabner et al. 2018). Similarly, MC also requires technology advancement in facing the complexity of business today. Even so, little discussions on the role of MC working together with ERP. These resources should not be implemented in isolation; instead, they have to be concurrent. The interaction between ERP and $\mathrm{MC}$ creates a unique complementarity effect that "represents an enhancement of resource value and arises when a resource produces a greater return in the presence of another resource than by itself" (Hsu 2013: 336). The stance renders ERP systems, MC and their complementarity effect are equally essential to building KS environment (Henri 2006; Alomari et al. 2018). In Malaysia, the importance of $\mathrm{KS}$ is discernible as the nation geared towards High-Income Country status by the year 2030, the need to pay close attention in managing knowledge-based industries is pertinent. It is a wellaccepted notion that Malaysian sustainable economic growth depends on all sectors, including manufacturing ability to move to higher-value activities generated through research and development (R\&D). Being creative and innovative throughout the manufacturing process is indispensable, especially in today's competitive market. Thus, investment in human capital and retaining the knowledge within the organisations are becoming critical, yet little understanding of the practices among Malaysian manufacturers, particularly in the digitalisation revolution era. Given that, building upon management control theory which puts the emphasis on information systems and accountability towards ensuring organizational sustainability and success, this study aims to examine the extent of ERP systems, MC and their complementarity effect in facilitating organisational KS practice.

This paper contributes to research on ERP and MC by examining their role in promoting organisational KS. Considering the emerging interest in discussing ERP from a business perspective (Huang et al. 2019; Rodriguez et al. 2020), this study adds knowledge to the theory and practice by exploring the attributes of ERP systems pertinent to the business users. Although ERP is undoubtedly valuable to the business, little discussion has been on the operationalisation of the systems (Sánchez-Rodríguez \& Spraakman 2012). Extending Scapens and Jayazeri's (2003) ERP framework, this study provides empirical support to clarify the relevance of ERP in the business process. Next, the study bridges the gap between ERP systems and MC and highlights their complementarity role towards KS, from Malaysian manufacturers' perspective. The case of Malaysia is relevant, though the nation is moving towards becoming a newly industrialised country, the motivation towards KS remains low (Omar \& Nordin 2016; Li et al. 2017; Chiu et al. 2018). The individuals' willingness to support organisational KS involve beyond sharing of information. $\mathrm{KS}$ is a process of stimulating exchange of thought and experience, and inevitably the elements of culture such as high-power distance and uncertainty avoidance may influence their business practice. Consequently, when it comes to sharing knowledge, they tend not to offer their knowledge to others (Pangil \& Nasruddin 2013). Hence, firms in the industry may need to better understand and motivate knowledge-sharing practices in the workplace.

This discussion continues with a review of the KS concept. The paper then deliberates on ERP and MC's role as a determining factor in facilitating KS and, subsequently, introduces the hypothesised relationships. The research method is discussed next. Finally, the findings are presented and discussed with some comments concerning the limitations and direction for future research. 
Literature Review And Hypotheses Development

\section{KNOWLEDGE SHARING}

KS has consistently garnered its importance over the last decades as organisational knowledge capital and their knowledge workers recognised as the critical factors for organisational success (Shao et al. 2012). The knowledge management capability is essential for organisational where KS is the source for firms to foster the capability and attain organisation's sustainable competitive advantage (Choi et al. 2016; Ritala et al. 2018; Chiu et al. 2018; Vătămănescu et al. 2020). Le and Lei (2019) accentuate that KS maximise organisational ability to manage knowledge and allows employees to work and achieve goals more efficiently. For that reason, strengthening a firm's abilities to share and apply knowledge, and subsequently transform the knowledge capital into outcomes is very important. The success rate mainly depends on the effectiveness of KS activities in an organisation as KS plays a decisive role in knowledge management (Pee \& Min 2017; Le et al. 2018; Chiu et al. 2018). Consistently, scholars and practitioners have increasingly emphasised the firm's ability to identify, capture, create, share or accumulate knowledge, also leveraging on the knowledge as it stimulates the creativity of its participants and enables the development of ideas (Nonaka \& Takeuchi 1995, Wang \& Wang 2012, Ali et al. 2019). Without knowledge, the organisation cannot function well, and for that reason, it is pertinent for firms to know how to utilise these resources effectively and efficiently. KS claimed to be the source of various organisational capabilities, including innovation which is vital for a firm's sustainability. Although sharing knowledge among colleagues may be difficult, it is the practical approach to create new knowledge (Maravilhas \& Martins 2019). Imparting experience among the people has a positive impact on business process such reducing the production costs, faster completion of new development projects, and enhancing firm's innovation capabilities, and overall performance including sales growth or revenue improvement from new products and services (Hansen et al. 2005; Mittal \& Dhar 2016). Accordingly, $\mathrm{KS}$, as a practice in modern organisations that result in thriving shared intellectual capital. The sharing of jobrelated knowledge will transform the knowledge captured at the individual to organisational knowledge, which Christensen (2007) describes as bridging organisational interdependence in conducting business processes. Once personal knowledge transformed into organisational knowledge, it has a better chance of being retained within the organisation.

KS is essential since it provides a link between individual and organisation by moving knowledge which resides it with individuals to the organisational level, where it is converted into economic and competitive value for the organisation (Dayan et al. 2017). The interactions among employees who possess diverse and different knowledge will enhance the organisation's ability to innovate far beyond what an individual can achieve. Moreover, Boland and Tenkasi (1995) find out that with the idea of KS, competitive advantage, and product success in organisations results from individuals whose diverse knowledge collaborating toward shared outcomes. Also, KS leads to disseminating innovative ideas that can be considered critical to creativity in the organisation, which contributes to both individual and organisational learning (Pangil \& Nasruddin 2013; Ahmed et al. 2021). These studies suggest that people's knowledge must be translated into organisational knowledge to operate effectively.

Knowledge can be in the form of tacit and explicit. Tacit knowledge represents the knowledge that people possess. Therefore, it may not be communicated easily or used without the person who is the knower. Whereas, explicit knowledge can be easily codified, stored at a single location, and transferred across time and space independent of individuals (Lam 2000). The increasing recognition of the importance of knowledge in organisations requires that both types of knowledge need to be retained and shared. Thus, even tacit knowledge must turn into explicit knowledge. Tacit knowledge is subjectively dealt with experience, while explicit is objective, a rational knowledge with standardised information and procedures captured in organisational knowledge databases (Maravilhas \& Martins 2019). Accordingly, Nonaka and Takeuchi (1995) describe the transformation from tacit to explicit knowledge is possible through the four-phase process. The process involves socialisation (i.e., the process of sharing experience); externalisation (i.e., dialogue and reflection from project manuals and team discussions); combination (i.e., combining different sets of explicit knowledge to create new knowledge); and internalisation (i.e., creating a systematic business process knowledge). Once done, it is easier to share, disseminate and communicate knowledge throughout the organisation.

\section{ENTERPRISE RESOURCE PLANNING SYSTEMS}

ERP systems are one of the most innovative developments in IT. Majority ERP definitions, taken from the IT perspective, describe the systems as a set of packaged application software modules with an integrated architecture that can be used by organisations as the primary engine for integrating data, processes and information technology, in real-time, across internal and external value chains (Motiwalla \& Thompson 2012; Zaglago et al. 2016; Bhumgara \& Sayyed 2017). Only recent the enterprise system has been viewed from users' perspective as Rouhani and Mehri (2018) and Rodriguez et al. (2020) depict ERP as an alternative for users' complex interface and disperse information systems standardise and automatise inter-functional transactions. Sánchez-Rodríguez and Spraakman (2012) criticise those businesses tend to concentrate on the information/report 
generated by the systems, without realising the usefulness of systems to improve the business process a broader perspective. Implementation of ERP systems may benefit businesses operational (i.e. facilitate business learning, empowerment, built common visions, harmonise interdepartmentalfunctioning, business learning, business involvement, mutual vision, better focus on core processes and employee satisfaction), management (i.e. better resource management, improved planning and decision making and continuous improvement), strategically (i.e. support business growth, support business alliance, build business innovations, build cost leadership, generate product differentiation, build external linkage and better information quality), and organisational aspects as a whole (i.e. cost reduction, cycle time reduction, productivity improvement, quality improvement, and customer services improvement, reduction in errors and improvement in speed of transactions processes) (Dantes \& Hasibuan 2011; Azevedo et al. 2012; Anaya 2019). ERP systems, an application of an integrated and automated business process, produce accurate and real-time information across the shared organisational database to create a competitive advantage (Alomari et al. 2018).

Scapens and Jayazeri (2003) normatively suggested a more comprehensive view in evaluating the attributes (i.e., integration, standardisation, centralisation and routinisation) of ERP systems from a business user's perspective. Integration is the prominent characteristic of ERP by which it minimises physical communication and coordination efforts between activities throughout the business processes. Acommon source of data, coupled with technology integration in the business process, facilitate information interchange among business units in the right manner (Rom \& Rohde 2007; Magal \& Word 2009; Granlund 2011). Integration attributes, however, cannot work in silos; it needs to be supported by a standardised business process to ease business actions and decision. Standardisation provides standard and repeated practices aimed at achieving the optimum degree of order in a given context. Such attributes are crucial since standardised expedite communication pertains to business operations, facilitates smooth handoffs across business units, allows comparative assessment and eventually creates business value (Davenport et al. 2004; Ramakumar \& Copper 2004). The degree of control over the system's functions being exercised by its users, and how much control retained by the highest authority is another aspect. An organisation is considered centralised when the business process decisions and control are kept at headquarter, whereas decentralised organisations delegate control to various organisational levels/functions. Acting as a formal communication channel amongst the people, the degree of ERP centralisation represents power distribution within the organisation (Jansen et al. 2006; Jaskyte 2011), which may influence the likeliness of distributing new knowledge. Routinisation is the last dimension by which ERP usage diffusion across organisational business processes reduces redundancies as routine tasks within firms are to be handled automatically. These processes are also referred to as ERP assimilation whereby the ERP implementation in an organisation encourages standardisation of business processes, allowing routine activities to be undertaken using system (Kharabe \& Lytinen 2012). Through routinisation, technology adoption encourages high quality and real-time approach and reduces the resource cost and input time. These benefits of having ERPs system unfortunately often have not been realised by firms due to the assimilation gap between the strategic decision to adopt and to use ERP systems in the business processes (Nam et al. 2019) meaning that the usefulness of the system has not been optimised. A similar discussion observes the pattern of ERP topic by which only integration attribute is acknowledged as the benefit of ERP. The inability to study wholesomeness of the system may lead to a piecemeal knowledge in discussing effective ERP systems. Extending Scapen and Jayazeri's argument, this study attempts to address the gap by examining the extent to which the ERP business process attributes has been assimilated in the business process and subsequently influence the KS practice.

\section{ENTERPRISE RESOURCE PLANNING AND KNOWLEDGE SHARING}

The creation of organisational knowledge requires a mechanism that can enable specific personal knowledge to be exchanged, evaluated, and integrated with others in the organisation during the adoption of an integrated information system. ERP systems contribute to the execution of organisational tasks by coordinating business processes and regulating business functions. In much as ERP systems focus on ideal practices, most organisations have to modify their work operations to compatible with ERP architecture (Chou et al. 2014), which demand to codify and store data. Such requirement inevitably captures the tacit knowledge as much as possible and turn it into explicit knowledge. The integration of ERP systems across firms supports the success of KS by providing a platform for organisational members to share the knowledge that an individual possesses about business processes and frameworks (Acar et al. 2017; Al-Ahbabi et al. 2017). Technology advancement has introduced the concept of virtual teamwork training, which can optimise knowledge transfer and reduce knowledge complexity more cost-effectively and efficiently (Del Giudice \& Maggioni 2014; Abbasi et al. 2015). The perspective is in parallel with the management control theory, which recognises that modern organisations communicate with a wide range of different stakeholders, and most importantly, firms need to adapt to the changing environment (Sljivic et al. 2015). Pragmatically, the ERP systems do affect significantly on the people, mainly through KS, and thus, the study posits that:

$\mathrm{H}_{1}$ : ERP systems are positively related to KS. 
Modern organizations communicate with a wide range of different stakeholders. For many of them, accounting-oriented control is neither the only, nor the most important type of control. This is particularly true for organizations that are looking for new business models, based mainly on innovations, in order to adapt to changed external circumstances. The need for a new framework of MC is obvious. Building this framework is slow and there is an evident gap between the theory of management control and managerial behaviour.

\section{MANAGEMENT CONTROL}

$\mathrm{MC}$ is a resource in creating sustainable competitive advantage. MC has been associated as an organisational resource as early as the year 1965 when Anthony described MC as the process by which resources are obtained and used effectively and efficiently to accomplish the organisation's objectives. MC renders cooperation among collectives of individuals or organisational units which share same objectives and guides efforts towards organisational goals $\mathrm{MC}$ has been seen as a tool designed to assist management decision entailing different types of approaches involving planning, budgeting, and analysing, measuring and evaluating useful information for proper decision making (Chenhall 2003; Cosenz \& Noto 2015). Although MC provide limit and decision space to control organisational members' behaviour (Birnberg \& Snodgrass 1988), empirical studies demonstrate that MC promotes innovation (Bisbe \& Otley 2004; Sa'adon et al. 2019). Whilst Kallunki et al. (2011) accentuate MC as an integrated information resource pertinent in directing and assessing firms' competitiveness. Irrespective there is no single universally accepted definition (Helsen et al. 2017; Said et al. 2017), generally MC has been acquainted with the integrative control mechanisms involving planning, decision making, monitoring and assessing the outcomes to ensure the attainment of organisational goals. The MC secure the mobilisation of individual and collective organisational resources towards specified directions. Thus, the people's behaviour, emotions and outputs need to be observed and dictated through organisational beliefs, value, policies, and procedures (Alvesson \& Karreman 2004, Mathar \& Gaur 2020). In controlling work behaviour, transparent design and supervision work process clarify the organisational expectation on them. Firms may directly control people's behaviour by setting standard and performance targets, referred to as technocratic control. The view is aligned with Jowarski and MacInnis's (1989) assertion that management control theory explains the match between job characteristics and the reliance on specific MC types, namely output, professional and self-control.

This form of control focuses on financial and human resources foresee that the result's elements, reward and punishment are crucial to guide organisational action and individual behaviour to be congruent with the organisational objectives (Widener 2004; Hansen et al.
2005). Alternatively, when a formal approach is less obvious, various socio-ideological control forms are likely to substitute or complement those gaps. Alvesson and Karreman (2004) associate socio-ideological control with the attempt to control the employees' mindsets. Thus, personnel and cultural controls ensure the organisation's values and assumptions are shared through socialisation, taking into account shared values and beliefs that guide norms or behaviour within the organisation (Merchant \& Van der Stede 2012; Voss \& Brettel 2014). The literature often portrays different MC styles, strengthening each other, challenging to be analysed separately. Given that, both the technocratic and socio-ideological styles should see as one form of MC (Cäker \& Siverbo 2014).

\section{MANAGEMENT CONTROL AND KNOWLEDGE SHARING}

MC plays a vital role in organisational learning. The understanding has been put forward in Simons's (1999) lever of control framework where traditional diagnostic control is associated with single-loop learning, while double-loop learning needs to be supported by interactive control. Similarly, forms of control encourage KS to enhance organisational learning. The form of control may stimulate KS. Result of formal control which resides in the financial and non-financial reports, for example, is a means of capturing explicit knowledge. Observing the staff hours of training can be a strategy to ensure transferring and accessibility to knowledge. The sharing experience also conducted informally during informal gatherings, unscheduled meetings and coffee break conversations; however, they need to be preceded by inculcating the KS culture. Meaning to say, the MC approach has a role in facilitating a firm's knowledgesharing effort (Grabner 2010; Massaro et al. 2014; Grabner et al. 2018) and therefore, it is hypothesised that:

$\mathrm{H}_{2}$ : MC is positively related to $\mathrm{KS}$

COMPLEMENTARITY OF ENTERPRISE RESOURCE PLANNING SYSTEMS AND MANAGEMENT CONTROL

It is crucial to observe the firm's competitive advantage dynamically by leveraging the existing resources (Barney 2001). Hamel and Prahalad (1993) identify five ways in leveraging strategic resources: concentration, accumulation, complementarity, conservation and recovery. Leverage through complementarity means that diverse resources and capabilities are blended to create a new skill combination that multiplies each component's value. Complementarity is a configuration or network of assets or resources, which enhances the resource than it does alone (Xu et al. 2006; Grabski \& Leech 2007; Fakoya \& Van Der Poll 2013; Hsu 2013). Complementarity denotes an improvement of resource value as a consequence when a resource produces greater returns in another resource's presence than by itself. On that basis, studies emphasise the notion that IT resource is prone to influence firms' performance only when it is 
utilised to create unique "complementarities" value with other IT or other firm resources (Rai et al. 2006; Fakoya \& Van Der Poll 2013; Hsu 2013). Besides, it is uncommon for technology to act alone in creating and sustaining strategic priorities.

Likewise, MC, which emphasises efficient resource utilisation in attaining the firm's objectives may not be possible without the support of technology. Even though ERP systems may not be the reason for adopting new control techniques, the technology improves the existing practices and expedites daily organisational tasks through automation. The ERP's standardisation attribute reduces the variations within-firm business process reporting facilitates the control of the activities. ERP strengthens the standardisation of daily tasks since it also facilitates the control of the input data and assists in monitoring deviations in employees' actions (Schermann et al. 2012) through a system preventing potential manipulations. Although such information is gathered in different departments, it can be accessed through the ERP within a short period. ERP enables the user to extract data across the whole organisation, which may contribute to MC's effective implementation. Chapman and Kihn (2009) stated that a significance for having ERP systems is that integrated information can be transferred and access without departmental boundaries. However, the security of the business information from internal and external threat never compromised. The automated ERP process can prevent the unauthorised data accessibility for information checking activities (Maraghini 2010), which are usually performed by the company's controllers for the MC purposes, and thus, the system may decrease the workload of the managers involved. The complementarity role of ERP may lead to efficient and effective resource usage given the integrated business process data may allow better control of the firm's asset values. Each resource-based success depends on the ability to fit with other resources to enhance resource visibility, transparency and utility (Lengnick-Hall et al. 2004; Mourouka \& Pussa 2015).

Although ERP implementation has positive consequences on $\mathrm{MC}$, the system is not a driver of change in the implementation of business activities, including the practice of sharing knowledge and experiences. The MC guide and monitor ensure that the people's behaviour and mindset align with the organisational belief towards KS. ERP systems, however, complement MC to facilitate the process. The system is an efficient medium to communicate the company's direction to all organisational member. The technology eases the sharing process as it provides a virtual learning environment such as virtual meeting and virtual training without requiring the employees' presence.

Given that employees may perform better when monitored, ERP provides visibility throughout the organisation (Mourouka \& Pussa 2015; Martins \& Santos 2021). The capacity of ERPs to encourage personal commitment to the organisation's goals is uncertain. Being technology, however, ERP cannot motivate employees to commit to organisational goals as motivation may be achieved throughout social interactions. The social aspects embedded in MC remain eminent in motivating the commitment and support from the people. Conversely, MC also act as a complementarity role towards ERP systems, by which the acceptance from the people determines the use of the technology. The combination of ERP and MC means not only technology that plays an important role, but also the human factor which is as equally important. Thus, the following hypothesis is proposed:

$\mathrm{H}_{3}$ : The complementarity between ERP systems and MC is positively related to $\mathrm{KS}$

The research framework is as shown in Figure 1.

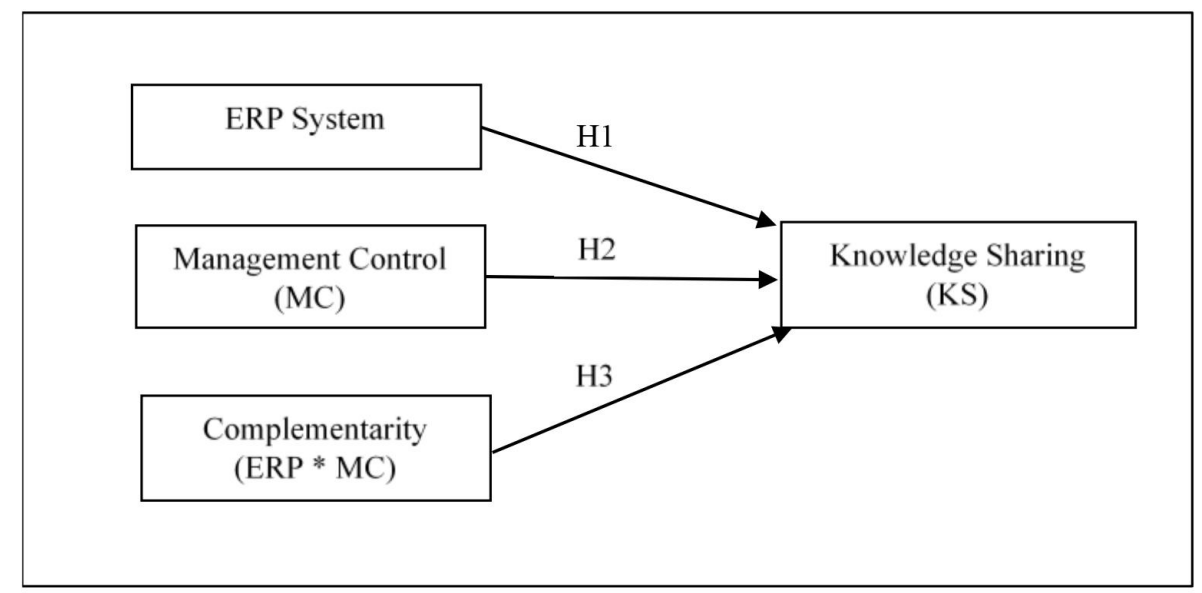

FIGURE 1. Research framework 


\section{Research Method}

SAMPLE

The sampling frame for this study was manufacturing firms listed in the Federation of Malaysian Manufacturers (FMM) Directory 2016. Samples were randomly selected from a total of 3879 firms using proportionate stratified sampling (FMM 2016). In this study, manufacturing sectors were selected due to the complexity and diversity, differentiating them from other sectors and their high level of industrial impact towards building up a highly competitive advantage that has resulted in the implementation of ERPs. Data were collected by administering a mail questionnaire survey over a-four- month duration between February to June 2016 to the top management with titles of chief executive officer, chief operating officer and controller of 972 selected manufacturing firms. They were preferred because they are considered the most likely to provide accurate and useful data on ERPs, MC and KS practices of their firms. Respondents were asked to identify whether their firms are implementing ERP systems. Only firms implementing the ERP systems proceeded to answer the survey questionnaire. Of this, 114 firms gave complete response giving a response rate of 11.73 per cent, which are sufficient to test the hypothesised relationships with a medium effect size (Cohen 1992). The sample representing all industries and sizes were the majority of locally owned firms.

TABLE 1. Respondents profile

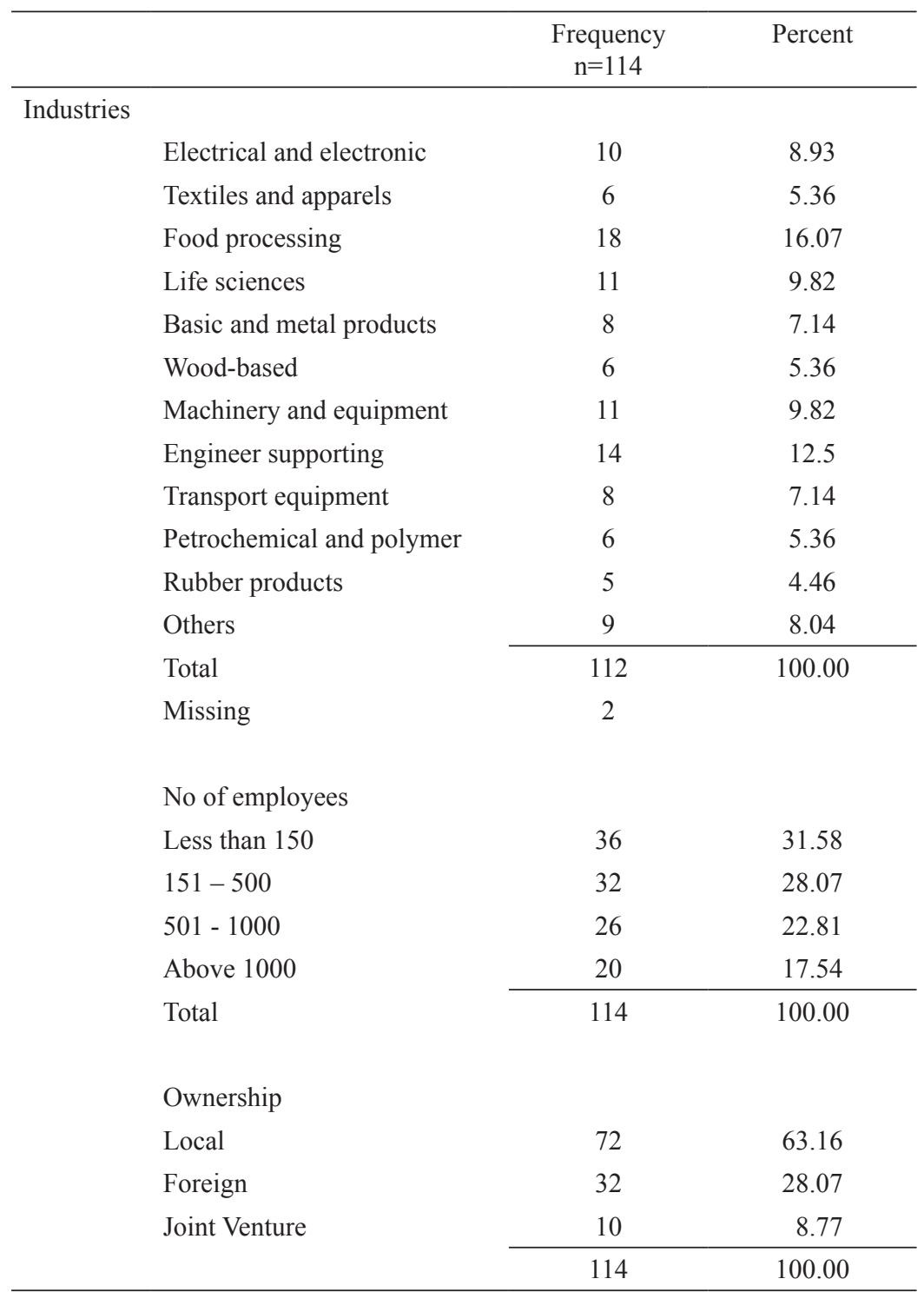




\section{MEASUREMENTS OF VARIABLES}

ERP is evaluated based on a combination of Magal and Word (2009), Sánchez-Rodríguez and Spraakman (2012), and Scapens and Jazayeri (2003) that consist of four business process attributes which are integration (17 items), standardisation (4 items), centralisation (7 items) and routinisation ( 7 items) of the business process. Respondents were asked the extent to which those items described their firm ERPs ranging from one (not at all) to seven (to a very great extent). However, for further statistical analysis, an average index of the attributes was used to measure ERP systems.

$M C$ is assessed through two main dimensions, technocratic and socio-ideological forms of control. A-twenty-item control approaches originally developed by Jaworski and MacInnis (1989) has been revised, modified and adapted by Hutzschenreuter and Israel (2009), and Kleine and Weibenberger (2014). Respondents were asked to indicate a seven-point scale Likert-type scale ranging from one (not at all) to seven (to a very great extent), the extent to which particular characteristics described their firms' MC. An average index of both dimensions was used for further analysis.

$K S$ is measured using a well-established 13 items instrument developed by Wang and Wang (2012) that observed the practice from the organisational level perspective. This instrument has been used many researchers from different areas (e.g., Alavi \& Leidner
2001; Reychav \& Weisberg 2010). The scale used for $\mathrm{KS}$ is a 7-point Likert Scale ranging from one (totally disagree) to seven (totally agree). Similarly, further statistical analysis was based on an average index.

The responses were analysed using the partial least squares (PLS) approach as it is recommended when (a) the objective is explaining and predicting target constructs and detecting, important driver constructs, (b) the structural model has formatively measured constructs, (c) the model is complex (with many constructs and indicators), and (d) the researcher is working with small sample size and data are potentially non-normal (Rigdon 2016: Hair et al. 2018). Hence, the reliability of the constructs needs to be evaluated by employing Cronbach's Alpha, Composite Reliability (CR) and Average Variance Extracted (AVE) (Hair et al. 2018) before assessing the quality of the measurement model. Detail of the factor loadings and Cronbach Alphas are presented in the subsequent section.

\section{RESULTS}

The descriptive statistics for the variables in this study are presented in Table 2. In general, the statistics show that all variable have mean greater than 4.0 , indicating that the distribution of scores skewed towards the agreement. The scales signify the likeliness of the presence of the ERP systems, MC, along with the KS effort among the manufacturers.

TABLE 2. Descriptive Statistics

\begin{tabular}{cccccc}
\hline & Items & Theoretical range & Actual range & Mean & Standard Deviation \\
\hline KS & 13 & $1-7$ & $2-7$ & 4.804 & 1.004 \\
ERP systems & 28 & $1-7$ & $2-7$ & 4.761 & 0.745 \\
MC & 20 & $1-7$ & $2-7$ & 4.816 & 0.751 \\
\hline
\end{tabular}

Table 3 shows that the Cronbach's alphas for all the constructs are above 0.80 , which are considered acceptable. Additionally, the $\mathrm{CR}$ values are in surplus of the cut-off point of 0.7 , and the AVE is above the 0.5 cut-off value reflect good convergent reliability, while all items loaded to their respective constructs are almost equivalent or exceeded the recommended value of 0.70 (Hair et al. 2014). Most items suggest good indicator reliability except for nine out of 37 items on ERP systems were dropped. These items are observing the attributes of the ERP systems.

TABLE 3. Summary of Estimation Measurement Model Parameters

\begin{tabular}{|c|c|c|c|c|c|}
\hline & Items & Factor Loadings & Cronbach's Alpha & $\mathrm{CR}$ & AVE \\
\hline \multirow[t]{6}{*}{ KS } & Invest in IT systems & 0.699 & 0.941 & 0.949 & 0.612 \\
\hline & Share experience & 0.701 & & & \\
\hline & Collect other's experience & 0.713 & & & \\
\hline & Share knowledge of know-where & 0.748 & & & \\
\hline & Offered training programs & 0.767 & & & \\
\hline & $\begin{array}{l}\text { Share reports and documents prepared by } \\
\text { organizational members }\end{array}$ & 0.773 & & & \\
\hline
\end{tabular}




\begin{tabular}{|c|c|c|c|c|c|}
\hline & Collect reports and documents from others & 0.802 & & & \\
\hline & Collect expert knowledge & 0.820 & & & \\
\hline & Encouraged by knowledge sharing mechanisms & 0.832 & & & \\
\hline & $\begin{array}{l}\text { Share reports and official documents with } \\
\text { organizational members }\end{array}$ & 0.835 & & & \\
\hline & Share lessons from past failures & 0.868 & & & \\
\hline & $\begin{array}{l}\text { Collect knowledge of know-where or know-whom } \\
\text { with others }\end{array}$ & 0.872 & & & \\
\hline & Share expert knowledge & 0.892 & & & \\
\hline \multirow[t]{32}{*}{ ERP } & Integration & & 0.938 & 0.948 & 0.645 \\
\hline & Users can easily browse the system & 0.716 & & & \\
\hline & Users are confident with the provided information & 0.778 & & & \\
\hline & $\begin{array}{l}\text { The systems allowed users to obtain complete } \\
\text { information }\end{array}$ & 0.801 & & & \\
\hline & Users believed in the provided information & 0.810 & & & \\
\hline & The system is easily accessed & 0.813 & & & \\
\hline & $\begin{array}{l}\text { Information without delay after occurrence of certain } \\
\text { event. }\end{array}$ & 0.827 & & & \\
\hline & Information is given automatically & 0.839 & & & \\
\hline & Data in appropriate language & 0.850 & & & \\
\hline & Data is maintained by the corporation & 0.850 & & & \\
\hline & Information is upon request & 0.861 & & & \\
\hline & Standardization & & 0.860 & 0.905 & 0.705 \\
\hline & Written rules and procedures & 0.809 & & & \\
\hline & $\begin{array}{l}\text { Rules and procedures specify how major tasks to be } \\
\text { done }\end{array}$ & 0.864 & & & \\
\hline & Written or unwritten procedures in performing work & 0.867 & & & \\
\hline & Following the standard operating procedures & 0.870 & & & \\
\hline & Centralization & & 0.932 & 0.945 & 0.712 \\
\hline & Tracking and control ERP projects. & 0.810 & & & \\
\hline & Approving requirements changes. & 0.827 & & & \\
\hline & Assignment of personnel to a project. & 0.839 & & & \\
\hline & Development of new systems. & 0.850 & & & \\
\hline & Assigning and dismissing of employee & 0.850 & & & \\
\hline & Selection of large investments. & 0.861 & & & \\
\hline & Budget allocations. & 0.867 & & & \\
\hline & Routinization & & 0.854 & 0.889 & 0.533 \\
\hline & Automation within major types of work & 0.672 & & & \\
\hline & Same job, in the same way & 0.703 & & & \\
\hline & Work is routine. & 0.733 & & & \\
\hline & Established procedures and practices. & 0.745 & & & \\
\hline & Same tasks from day to day. & 0.751 & & & \\
\hline & Automated process & 0.754 & & & \\
\hline & An understandable sequence of steps. & 0.767 & & & \\
\hline \multirow[t]{4}{*}{$\mathrm{MC}$} & Technocratic Control & & 0.931 & 0.943 & 0.673 \\
\hline & Superiors defining & 0.764 & & & \\
\hline & Superior's monitoring & 0.812 & & & \\
\hline & Superiors providing information on achievement. & 0.815 & & & \\
\hline
\end{tabular}




\begin{tabular}{lll}
... continued & & \\
\hline Performance goals are controlled & 0.817 \\
Potential performance goals deviations & 0.835 & \\
Goals are established for employees. & 0.838 & \\
Variable remuneration components & 0.839 & 0.933 \\
Superiors evaluating & & 0.943 \\
Socio-ideological Control & 0.756 & \\
Training and development activities & 0.760 \\
Mission statement conveys the values & 0.765 \\
Hiring best-suited applicants & 0.772 \\
Sharing informal codes & 0.785 & \\
Employee's aware firm's core values. & 0.789 \\
Establishing recruiting process & 0.803 \\
Employees are carefully selected & 0.811 & \\
Employee's skills. & 0.817 & \\
Top manager's communication & 0.829 \\
Employees perceive the values & & \\
\hline
\end{tabular}

Meanwhile, the adequacy of the constructs' discriminant validity is assessed using Fornell-Larcker criterion approach where the square root of each construct's AVE is greater than its highest correlation with any other construct. As shown in Table 4, the reported values demonstrate the validity of all constructs used in the study. All constructs are significantly correlated strongly and positively with KS suggesting that each of these constructs may result in better KS. Meanwhile intercorrelations of those constructs in the model did not override the square root of the AVE support the constructs' discriminant validity. The psychometric properties of the instruments were acceptable, and thus supported the study's constructs validity.

TABLE 4. Discriminant Validity Coefficients

\begin{tabular}{cccccccc}
\hline & KS & ERP-I & ERP-S & ERP-C & ERP-R & MC-T & MC-S \\
\hline KS & 0.782 & & & & & & \\
ERP-I & $0.779^{* *}$ & 0.803 & & & & & \\
ERP-S & $0.689^{* *}$ & $0.550^{* *}$ & 0.804 & & & & \\
ERP-C & $0.788^{* *}$ & $0.778^{* *}$ & $0.560^{* *}$ & 0.844 & & & \\
ERP-R & $0.578^{* *}$ & $0.491^{*}$ & $0.581^{* *}$ & $0.545^{* *}$ & 0.730 & & \\
MC-T & $0.780^{* *}$ & $0.682^{* *}$ & $0.687 * *$ & $0.668^{* *}$ & $0.576^{* *}$ & 0.820 & 0.789 \\
MC-S & $0.779 * *$ & $0.711^{* *}$ & $0.627^{* *}$ & $0.773^{* *}$ & $0.548^{* *}$ & $0.766^{* *}$ & 0.789 \\
\hline
\end{tabular}

The square root of the AVE value for each of the constructs along the diagonal (in bold)

$* * \mathrm{p}<0.01 ; * \mathrm{p}<0.05$ (two-tailed test)

\section{HYPOTHESES TESTING}

Past studies (Ravichandran et al. 2005; Hsu 2013) has observed the complementarity as resource improvement stem from the interaction between resources. The complementarity effect is operationalised using multiplicative terms in statistical analysis. Consistent with the approach taken by other research (e.g., Rai et al. 2006; Ravichandran et al. 2005; Hsu 2013; Ruivo et al. 2017.), the complementarity between ERP systems and MC is analysed by multiplying both resources' average index (i.e., ERP systems * MC). The significant path coefficients for all four attributes of ERP systems ( $p$ 0.001) provide support towards Scapen and Jayazeri's proposition. Figure 2 depicts the model's path coefficient, and the summarised results of the hypotheses testing are presented in Table 5. 


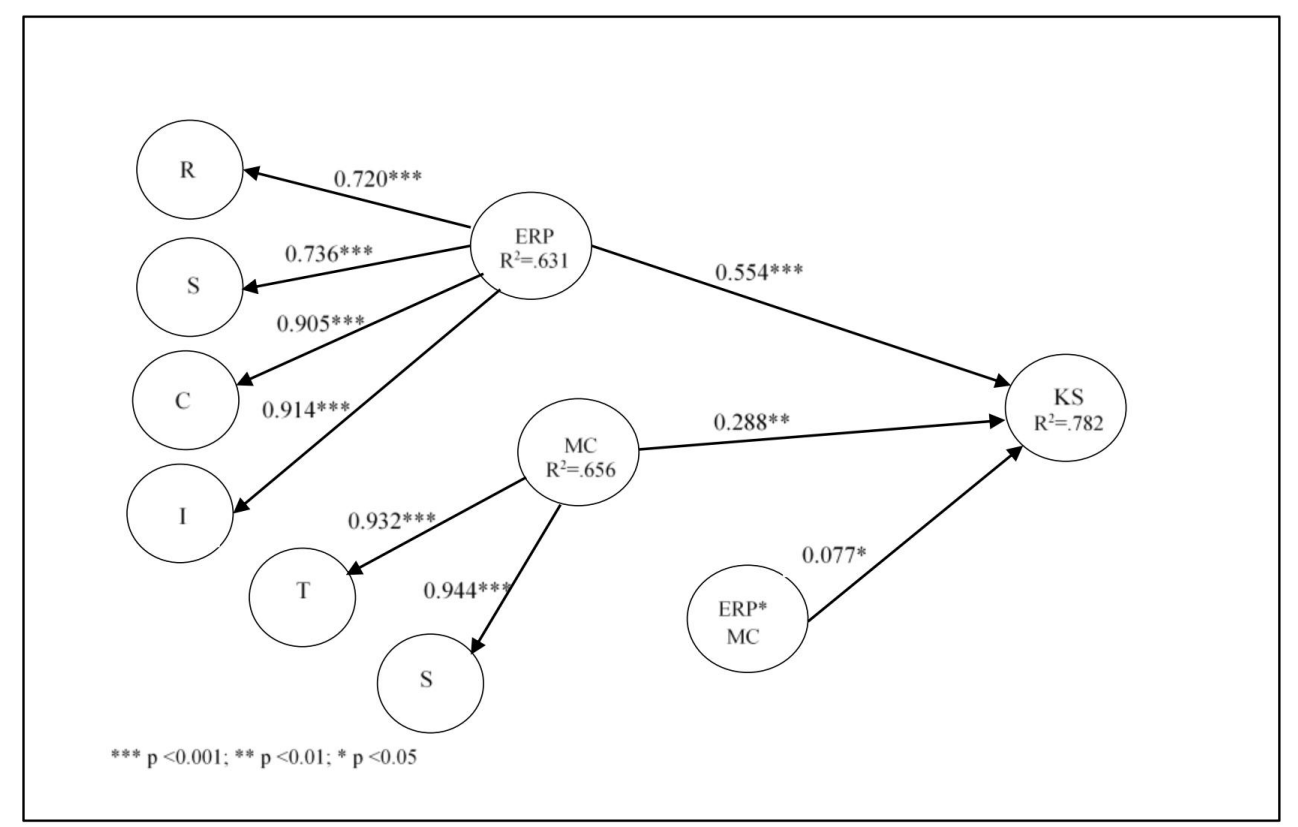

FIGURE 2. Path Coefficient Model

TABLE 5. Summarized Hypotheses Testing Results

\begin{tabular}{cccccc}
\hline Hypothesis & Relationship & Coefficient & t-value & Results & $\mathrm{f}^{2}$ \\
\hline H1 & ERP - > KS & 0.554 & $6.433^{* * *}$ & Supported & 0.416 \\
H2 & MC -> KS & 0.288 & $3.933^{* *}$ & Supported & 0.164 \\
H3 & ERP*MC - $>$ KS & 0.077 & $1.725^{*}$ & Supported & 0.026 \\
\hline
\end{tabular}

*** $\mathrm{p}<0.01 ; * * \mathrm{p}<0.01 ; * \mathrm{p}<0.05$ (two-tailed test)

$\mathrm{H}_{1}, \mathrm{H}_{2}$ and $\mathrm{H}_{3}$ posited that ERP, MC and their complementarity effect are positively associated with KS. The summarised results (refer to Figure 2 and Table 5) substantiate that technology, control system, and their combine effect support the knowledge-sharing practice. Besides the statistical significance of P-value, the effect sizes $\left(\mathrm{f}^{2}\right)$ are also essential to be reported. For measuring the magnitude of the effect size, Cohen's (1992) guideline is used, which are $0.02,0.15$, and 0.35 , representing small, medium, and large effects. Table 5 shows that the two hypotheses, ERP $\left(\mathrm{f}^{2}=0.474\right)$, and MC $\left(\mathrm{f}^{2}=0.164\right)$, have large and medium effects on KS, respectively. The effect size of the complementary between ERP and MC on KS is considered small $\left(\left(\mathrm{f}^{2}=0.026\right)\right.$. It can be concluded that all hypotheses are supported. The results are consistent with Acar et al. (2017) and Massaro et al. (2014) that reported significant relationships between the ERP and $\mathrm{KS}$, and MC and KS. At the same time, the study extends the knowledge by providing evidence on ERP and MC's combined effect on sharing knowledge. Despite the small effect size, the findings suggesting the complementarity effect does affect the KS practice in firms which may need to be investigated further.

\section{Discussion And Conclusion}

The KS practices among the people, groups and across functional areas are crucial for firms to create, share, capture, and apply the knowledge that enables organisations to improve resource structuring and capacity building. The sharing process through dialogue, discussion, and socialisation required the necessary infrastructure to support and facilitate the knowledge exchange process. Both the ERP, providing the KS sharing platform, and $\mathrm{MC}$, a mechanism to govern KS practice, are positively associated with KS. The first finding consistent with past studies (Chou et al. 2014; Zaglago et al. 2016; Mirzaee \& Ghaffari 2018) demonstrates that ERP improves sharing and integrity of knowledge and information in the firms. A case study in a manufacturing firm in Selangor reveals that there are incidences where organisational knowledge in the organisation was lost, due to the knowledge not adequately managed (Kamal et al. 2020). Most of the manufacturers acknowledge the pertinent of ERP to assist their business operations, managerial function and strategic decision. The FMM also expresses a similar view that local manufacturers have to move towards high-value manufacturing 
activities, especially in the present Industry 4.0 era. The expectation that ERP deployment may yield significant business benefits for a sustainable long-term growth strategy and enable them to compete in the global market. As there is no one-size fit all manufacturers in Malaysia, the process of exploring, evaluating and deploying an ERP system becomes paramount, especially for the local manufacturers especially to the SMEs that are new to it. Each of the ERP attributes, centralisation, standardisation, routinisation and integration of the business process creates and eases the firms' sharing environment. Besides storing explicit knowledge in a structured manner, the system smooths the process in transforming tacit into explicit knowledge to safeguard against the loss of knowledge capital stemming from employee mobility. Henceforth, ERP support firms to make the knowledge stored in the human brain or on documents available to all staff and employees of the organisation.

Industry 4.0 is perceived to rely heavily on technological advancements in hardware and software. However, FMM continues to advocate skilled human capital as a critical success factor in Malaysia's sustainable competitive advantage. Thus, the people's willingness to support the organisational values, sharing knowledge is equally important, and to safeguard a goal congruence between the firm and the people, MC plays a significant role. The finding confirms MC's role in providing the behavioural control procedures, which align with the literature (Shurafa \& Mohamed 2016; Mathar \& Gaur 2020). MC guides the process through the result and action controls and promotes the belief and right attitude in sharing knowledge. MC drives collectivism, social trust, shared goal and self-efficacy as the emerged organisational value. Overall, the finding indicates that KS among employees in Malaysia's manufacturing firms is gaining grounds. The presence of ERP technology, together with a proper way of control offers a new perspective of sharing knowledge and experience. The technology reduces the challenge and barrier while improving the accessibility of information. Whereas, the control elements oversee the motivation and commitment of the employees towards KS. The dynamic of having ERP and MC can be observed through the complementarity effect. The leverage on both ERP and MC practices extends the organisation capacity to support KS.

Nevertheless, not many manufacturing in Malaysia has leveraged the potential benefits of both resources. The strong motivation for better leveraging ERP and MC, suggesting the synergy between them, may help share and build organisational knowledge capabilities. Minimal discussion on the integration between ERP and MC, which mostly their presence in the Malaysian manufacturing sector, are examined separately. The small effect of the findings reported in this study substantiate on the argument. The positive relationship between ERP and MC complementarity effect and KS poses the possibility of creating a synergy by the presence of both resources in facilitating KS practice among the manufacturing firms in Malaysia. Besides the evidence extends the theory by providing empirical explaining with the positive effect of the complementarity between ERP and MCS on KS, it unfolds another dimension of KS enabler to be explored by the firms.

However, there are limitations to be surrendered when concluding the findings of this study. First, concerning the study's objective to observe the practice of KS among manufacturing organisations on a broad scale, unquestioningly limits the ability to go in-depth. The trade-off between broad scope and in-depth investigation results in a limited understanding of the variables under study. Moreover, the relatively small sample size requires the generalisation of finding needs to be made with caution. Even though this study's analyses include the necessary conditions for the proof of predictive relevance and causal relationships, a larger sample size may yield robust results. Second, the limitation stems from the cross-sectional nature of data collection. Collecting data at a single point of time in dealing with a dynamic issue, ERP, in particular, provides a snapshot of the practices. Inevitably, the responses are greatly affected by the conditions existing at that time, which may be different if data is collected at a different point of time. Although the survey addressed the firm's top management, the actual respondents may be unfamiliar with the details of the information required when responding to some of the survey items is another limitation underpinning the study. Thus, the results should be interpreted with necessary caution. Future study should focus on overcoming the limitations of the present study.

Nonetheless, this research does open up opportunities for future research on understanding the association between ERPs and MC. Given the change in the business operations as an impact of the global pandemic, a contemporary perspective on the use of technology and MC practices to support the new working style needs to be further explored to understand the findings further. It would be interesting to know the study's applicability in other countries as this study is strictly on Malaysia manufacturers. Accordingly, similar research in other sectors, such as services and the public sector may increase the current study's generalizability. Notwithstanding, this study provides a future longitudinal study in ERP, MC and their complementary effect towards organisational success.

\section{REFERENCES}

Abbasi, M. S., Tarhini, A., Elyas, T. \& Shah, F. 2015. Impact of individualism and collectivism over the individual's technology acceptance behaviour: a multi-group analysis between Pakistan and Turkey. Journal of Enterprise Information Management 28(6): 747-768.

Acar, M. F., Tarim, M., Zaim, H., Zaim, S. \& Delen, D. 2017. Knowledge management and ERP: complementarity or contradictory? International Journal of Information Management 37(6): 703-712. 
Ahmet Demir, Taylan Budur, Hiwa M. Omer \& Almas Heshmati 2021. Links between knowledge management and organisational sustainability: does the ISO 9001 certification have an effect?. Knowledge Management Research \& Practice DOI: 10.1080/14778238.2020.1860663

Al-Ahbabi, S., Singh, S. K., Gaur, S. S. \& Balasubramanian, S. 2017. A knowledge management framework for enhancing public sector performance. International Journal of Knowledge Management Studies 8(3/4), 329-350.

Alavi, M. \& Leidner, D. E. 2001. Knowledge management and knowledge management systems: conceptual foundations and research issues. MIS Quarterly: 107-136.

Ali, A. A., Selvam, D. Paris, L. \& Gunasekaran, A. 2019. Key factors influencing knowledge sharing practices and its relationship with organisational performance within the oil and gas industry. Journal of Knowledge Management 23(9): 1806-1837.

Alomari, I.A., Amir, A.M., Aziz, K.A. \& Auzair, S.M. 2018. Effect of Enterprise Resource Planning systems and forms of control on the firm's competitive advantage. Asian Journal of Accounting \& Governance 9: 87-97.

Alvesson, M. \& Kärreman, D. 2004. Interfaces of control: technocratic and socio-ideological control in a global management consultancy firm. Accounting, Organisations and Society 29(3-4): 423-444.

Amid, A., Moalagh, M. \& Ravasan, A.Z. 2012. Identification and classification of ERP critical failure factors in Iranian industries. Information Systems 37(3): 227-237.

Anand, A. \& Walsh, I. 2016. Should knowledge be shared generously? Tracing insights from past to present and describing a model. Journal of Knowledge Management 20(4): 713-730.

Anaya, L. 2019. To what extent is it viable to apply benefits management approach for ERP systems? Procedia Computer Science 164: 33-38

Anthony, R. N. 1965. Planning and Control Systems: A Framework for Analysis. Division of Research. Graduate School of Business Administration, Harvard University.

Appelbaum, D., Kogan, A., Vasarhelyi, M. \& Yan, Z. 2017. Impact of business analytics and enterprise systems on managerial accounting. International Journal of Accounting Information Systems 25: 29-44.

Azevedo, P. S., Romão, M. \& Rebelo, E. 2012. Advantages, limitations and solutions in the use of ERP Systems (Enterprise Resource Planning)-a case study in the hospitality industry. Procedia Technology 5: 264-272.

Barney, J. 2001. Resource-based theories of competitive advantage: A tenure retrospective on the resource-based view. Journal of Management 27: 643-650.

Bhumgara, A. \& Sayyed, I. 2017. Enterprise resource planning systems. International Journal of Advances in Engineering \& Technology 10(2): 283-284

Bisbe, J. \& Otley, D. 2004. The effects of interactive use of management control systems on product innovation. Accounting, Organisations and Society 29: 709-737.

Bley, K., Leyh, C. \& Schäffer, T. 2016. Digitisation of German enterprises in the production sector-do they know how "digitised" they are? Proceedings of the $22^{\text {nd }}$ American Conference on Information Technology (AMCIS 2016): 1-10.

Boland Jr, R. J. \& Tenkasi, R. V. 1995. Perspective making and perspective taking in communities of knowing. Organization Science 6(4): 350-372
Cäker, M. \& Siverbo, S. 2014. Strategic alignment in decentralised organisations-the case of Svenska Handelsbanken. Scandinavian Journal of Management 30(2): 149-162.

Christensen, P. H. 2007. Knowledge sharing: moving away from the obsession with best practices. Journal of Knowledge Management 11(1): 36-47.

Chapman, C. S. \& Kihn, L.A. 2009. Information system integration, enabling control and performance. Accounting, Organisations and Society 34(2): 151-169.

Chenhall, R. H. 2003. Management control systems design within its organisational context: findings from contingency-based research and directions for the Future. Accounting, Organisations and Society 28(2-3): 127-168.

Chou, H.W., Lin, Y.H., Lu, H.S., Chang, H.H. \& Chou, S.B. 2014. Knowledge sharing and ERP system usage in the post-implementation stage. Computers in Human Behavior 33(1): 16-22.

Chiu, C.K, Lin, C.P, Tsai, Y.H \& Teh, S.F. 2018. Enhancing knowledge sharing in high-tech firms the moderating role of collectivism and power distance. Cross Cultural \& Strategic Management 25(3): 468-491.

Choi, S.B., Kim, K., Ullah, S.E. \& Kang, S.W. 2016. How transformational leadership facilitates innovative behavior of Korean workers: examining mediating and moderating processes. Personnel Review 45(3): 459-479.

Cohen, J. 1992. Quantitative methods in psychology: a power primer. Psychological Bulletin 112(1): 155-159.

Cleary, P. \& Quinn, M. 2016. Intellectual capital and business performance: an exploratory study of the impact of cloudbased accounting and finance infrastructure. Journal of Intellectual Capital 17(2): 255-278.

Cosenz, F. \& Noto, L. 2015. Combining system dynamics modelling and management control systems to support strategic learning processes in SMEs: a dynamic performance management approach. Journal of $\mathrm{KNO}$ $26(2 / 3), 225-248$.

Dantes, G. R. \& Hasibuan, Z. A. 2011. The impact of Enterprise Resource Planning (ERP) system implementation on organisation: case study ERP implementation in Indonesia. IBIMA Business Review 11(1):1-10.

Davenport, T. H. 1998. Putting the enterprise into the enterprise system. Harvard Business Review 76(4): 121-131

Davenport, T. H., Harris, J. G. \& Cantrell, S. 2004. Enterprise systems and ongoing process change. Business Process Management Journal 10(1): 16-26.

Dayan, R., Heisig, P. \& Matos, F. 2017. Knowledge management as a factor for the formulation and implementation of organisation strategy. Journal of Knowledge Management 21(2): 308-329.

Del Giudice, M. \& Maggioni, V. 2014. Managerial practices and operative directions of knowledge management within inter-firm networks: a global view. Journal of Knowledge Management 18(5): 841-846.

Fakoya, M. B. \& Van Der Poll, H. M. 2013. Integrating ERP and MFCA systems for improved waste-reduction decisions in a brewery in South Africa. Journal of Cleaner Production 40(2):136-140.

FMM. 2016. Malaysian Industries 47th Ed, Federation of Malaysian Manufacturers. Kuala Lumpur. 
Forbes ( $25^{\text {th }}$ June 2019). The Job-Jumping Generation: Mistakes Millennials Are Making When Changing Jobs. Retrieved $29^{\text {th }}$ February 2020 from https://www.forbes.com/sites/ ericbrotman/2019/06/25/the-job-jumping-generationmistakes-millennials-are-making-when-changingjobs/\#7a88a273313d

Grabner, I. 2010. The impact of creativity dependency on MCS design contrasting creative and non-creative industries. European Accounting Association, Istanbul.

Grabner; I., Posch, A. \& Wabnegg, M. 2018. Materialising innovation capability: a management control perspective. Journal of Management Accounting Research 30 (2): 163-185.

Grabski, S. V. \& Leech, S. A. 2007. Complementarity controls and ERP implementation success. International Journal of Accounting Information Systems 8(1): 17-39.

Grag, P. \& Grag, A. 2013. An empirical study on critical failure factors for enterprise Resource Planning in Indian retail sector. Business Process Management Journal 19(3): 496-514.

Granlund, M. 2011. Extending AIS research to management accounting and control issues: a research note. International Journal of Accounting Information Systems 12(1): 3-19.

Griffin, P. A. \& Wright, A. M. 2015. Commentaries on big data's importance for accounting and auditing. Accounting Horizons 29(2): 377-379.

Hair, J. F., Sarstedt, M., Ringle, C. M. \& Gudergan, S. P. 2018. Advanced Issues in Partial Least Squares Structural Equation Modeling. Los Angeles, CA: Sage.

Hamel, G. \& Prahalad, C. K. 1993. Strategy as stretch and leverage. Harvard Business Review 71(2): 75-84.

Hansen, M. T., Mors, M. L. \& Løvås, B. 2005. Knowledge sharing in organisations: multiple networks, multiple phases. Academy of Management Journal 48(5): 776-793.

Helsen, Z., Lybaert, N., Steijvers, T., Orens, R. \& Dekker, J. 2017. Management control systems in family firms: a review of the literature and directions for the future. Journal of Economic Survey 31(2): 410-435.

Henri, J. 2006. Management control systems and strategy: a resource-based perspective. Accounting, Organisations and Society 31: 529-558.

Hsu, P.F. 2013. Integrating ERP and e-Business: resource complementarity in business value creation. Decision Support Systems 56(4): 334-347.

Huang, S. Y., Chiu, A. A., Chao, P. C. \& Arniati, A. 2019. Critical success factors in implementing enterprise resource planning systems for sustainable corporations. Sustainability 11(23): 67-85.

Hutzschenreuter, T. \& Israel, S. 2009. A review of empirical research on dynamic competitive strategy. International Journal of Management Review 11(4): 421-461.

Jansen, J. J., Van Den Bosch, F. A. \& Volberda, H. W. 2006. Exploratory innovation, exploitative innovation, and performance: Effects of organisational antecedents and environmental moderators. Management Science 52(11): 1661-1674.

Jayawickrama,U., Liu, S., Smith, H., Akhtar, P. \& Al Bashir, M.D. 2019. Knowledge retention in ERP implementations: the context of UK SMEs. Production Planning \& Control 30: 1032-1047.

Jaskyte, K. 2011. Predictors of administrative and technological innovations in nonprofit organisations. Public Administration Review 71(1): 77-86.
Jaworski, B. J. \& Macinnis, D. J. 1989. Marketing jobs and management controls: toward a framework. Journal of Marketing Research 26(4): 406-419.

Kamal P.N.M., Buniyamin N., \& Osman A. 2020. Current Knowledge Management Activities in a Manufacturing Company in Malaysia: A Case Study. In Emerging Trends in Intelligent Computing and Informatics edited by Saeed F., Mohammed F., Gazem N. IRICT 2019. Advances in Intelligent Systems and Computing, Cham: Springer.

Kallunki, J.-P., Laitinen, E. K. \& Silvola, H. 2011. Impact of Enterprise Resource Planning Systems on management control systems and firm performance. International Journal of Accounting Information Systems 12(1): 20-39.

Kharabe, A. \& Lyytinen, K. J. 2012. Is implementing ERP like pouring concrete into a company? Impact of enterprise systems on organisational agility. International Conference on Information Systems: 1-20.

Kleine, C. \& Weißenberger, B. E. 2014. Leadership impact on organisational commitment: the mediating role of management control systems choice. Journal of Management Control 24(3): 241-266.

Lam, A. 2000. Tacit knowledge, organisational learning and societal institutions: an integrated framework. Organisation Studies 21(3): 487-513.

Le, P. B. \& Lei, H. 2019. Determinants of innovation capability: The roles of transformational leadership, knowledge sharing and perceived organisational support. Journal of Knowledge Management 23(3): 527-547.

Le, P.B., Lei, H. \& Than, T.S. 2018. How leadership and trust in leaders foster employees behavior toward knowledge sharing. Social Behavior and Personality: An International Journal 46(5): 705-720.

Lengnick-Hall, C. A., Lengnick-Hall, M. L. \& AbdinnourHelm, S. 2004. The role of social and intellectual capital in achieving competitive advantage through Enterprise Resource Planning (ERP) Systems. Journal of Engineering and Technology Management 21(4): 307-330.

Lin, H. 2007. Knowledge sharing and firm innovation capability: An empirical study. International Journal of Manpower 28(3/4): 315-332.

Li, S., Park, S.H. \& Selover, D.D. 2017. The cultural dividend: a hidden source of economic growth in emerging countries. Cross Cultural \& Strategic Management 24(4): 590-616.

Magal, S. R. \& Word, J. 2009. Essentials of Business Processes and Information Systems. New Jersey: Wiley Publishing.

Malmi, T. \& Brown, D.A. 2008. Management control systems as a package - opportunities, challenges and research directions. Management Accounting Research 19: 287-300.

Maraghini, M. P. 2010. New integrated information systems and management control change in small and medium enterprises. Business Performance Measurement and Management: 13-37

Maravilhas, S. \& Martins, J. 2019. Strategic knowledge management in a digital environment: Tacit and explicit knowledge in Fab Labs. Journal of Business Research 94: 353-359.

Martins, J.L. \& Santos, C. 2021. The influence of ERP systems on organizational aspects of accounting: case studies in Portuguese companies. Accounting Research Journal (Artcle in press)

Massaro, M., Pitts, M., Zanin, F. \& Bardy, R. 2014. Knowledge sharing, control mechanisms and intellectual liabilities in knowledge-intensive firms. The Electronic Journal of Knowledge Management 12(2): 110-121. 
Mathar, D. \& Gaur, M. 2020. Change management: identifying change agents using social network analysis in an ERP implementation. International Journal of Computer Engineering and Technology (IJCET) 11(1): 1-9.

Merchant, K. A. \& Van der Stede, W. A. 2012. Management Control Systems: Performance Measurement, Evaluation And Incentives. London: Pearson Education.

Mirzaee, S. \& Ghaffari, A. 2018. Investigating the impact of information systems on knowledge sharing. Journal of Knowledge Management 22(3): 501-520

Mittal, S. \& Dhar, R. L. 2016. Effect of green transformational leadership on green creativity: a study of tourist hotels. Tourism Management 57(1): 118-127.

Motiwalla, L. F. \& Thompson, J. 2012. Enterprise Systems for Management. Boston, MA: Pearson.

Mourouka, A. \& Pussa, A. 2015. Mind the gap: the interplay between management control and enterprise resource planning. Unpublished thesis Master's Programme in Accounting and Management Control, school of Economics and Management, Lund University.

Muthuveloo, R., Shanmugam, N. \& Teoh, A.I. 2017. The impact of tacit knowledge management on organisational performance: Evidence from Malaysia. Asia Pacific Management Review 22(4): 192-201.

Nam, Y., Kang, G. \& Hong, U. 2019. The neural correlates of lexical markedness and the truth value: An ERP study on the processing of Korean comparative sentences. $25^{\text {th }}$ Architectures and Mechanism of Language Proceeding Conference.

Nonaka, I. \& Takeuchi, H. 1995. The Knowledge-Creating Company: How Japanese Companies Create the Dynamics of Innovation. New York: Oxford University Press.

Omar, S. \& Noordin, F. 2016. Moderator influences on individualism-collectivism and career adaptability among ICT professionals in Malaysia. Procedia Economics and Finance 37: 529-537.

Pan, B., Hembrooke, H., Joachims, T, Lorigo, L., Gay, G. \& Granka, G. 2007. In Google we trust: users' decisions on rank, position, and relevance. Journal of ComputerMediated Communication 12(3): 801-823.

Pangil, F. \& Nasruddin, M. A. 2013. Knowledge and the importance of knowledge sharing in organisations. Proceedings of Conference on Business Management Research, UUM.

Pee, L. \& Min, J. 2017. Employees' online knowledge sharing: the effects of person-environment fit. Journal of Knowledge Management 21(2): 432-453.

Presenza, A., Abbate, T. \& Meleddu, M. 2017. Small-and medium-scale Italian winemaking companies facing the open innovation challenge. International Small Business Journal 35(3): 327-348.

Rai, A., Patnayakuni, R. \& Seth, N. 2006. Firm performance impacts of digitally enabled supply chain integration capabilities. MIS Quarterly 30(2): 225-246.

Ramakumar, A. \& Cooper, B. 2004. Process standardisation proves profitable. Quality 43(2): 42-54.

Ravichandran, T., Lertwongsatien, C. \& Lertwongsatien, C. 2005. Effect of information systems resources and capabilities on firm performance: a resource-based perspective. Journal of Management Information Systems 21(4): 237-276.
Redman, A. 2018. Harnessing the Sustainable Development Goals for Businesses: a progressive framework for action. Business Strategy and Development 9(4): 230-243.

Rigdon, E. E. 2016. Choosing PLS path modeling as analytical method in European management research: A realist perspective. European Management Journal 34(6): 598-605.

Ritala, P., Husted, K., Olander, H. \& Michailova, S. 2018 External knowledge sharing and radical innovation: the downsides of uncontrolled openness. Journal of Knowledge Management 22(5): 21104-1123.

Rodriguez, R., Molina-Castillo, F. J. \& Göran S. 2020. Enterprise resource planning and business model innovation: process, evolution and outcome. European Journal of Innovation Management 84: 328-341.

Rom, A. \& Rohde, C. 2007. Management accounting and integrated information systems: a literature review. International Journal of Accounting Information Systems 8(1): 40-68.

Rouhani, S. \& Mehri, M. 2018. Empowering benefits of ERP systems implementation: empirical study of industrial firms. Journal of Systems and Information Technology 20(1): 54-72.

Ruivo, P., Oliveira, T. \& Neto, M. 2017. Examine ERP postimplementation stages of use and value, empirical evidence from Portuguese SMEs. International Journal of Accounting Information Systems 15(2): 166-184.

Sa'adon, S., Amir, A.M. \& Amiruddin, R. 2019. Management control system and innovation: implication for Malaysian manufacturing innovation performance. Asian Journal of Accounting \& Governance 12: 155-168.

Said, N.A., Amir, A.M. \& Maelah, R. 2017. The level of professionalism and the use of PMS among managers in Malaysian manufacturing firms. Asia-Pacific Management Accounting Journal 12(2): 1-23.

Sánchez-Rodríguez, C. \& Spraakman, G. 2012. ERP systems and management accounting: a multiple case study Qualitative Research in Accounting \& Management 9(4): 398-414.

Scapens, R. W. \& Jazayeri, M. 2003. ERP Systems and management accounting change: opportunities or impacts? a research note. European Accounting Review 12(1): 201-233.

Schermann, M., Wiesche, M. \& Krcmar, H. 2012. The role of information systems in supporting exploitative and exploratory management control activities. Journal of Management Accounting Research 24(1): 31-59.

Shao, Z., Feng, Y. \& Liu, L. 2012. The mediating effect of organisational culture and knowledge sharing on transformational leadership and enterprise resource planning systems success: an empirical study in China Computers in Human Behavior 28(6): 2400-2413.

Shurafa, R. \& Mohamed, R. B. 2016. Management control system, organisational learning, and firm's performance: An empirical study from developing economy. International Journal of Advanced and Applied Sciences 3(10): 79-88.

Sljivic, S., Skorup, S. \& Vukadinovic, P. 2015. Management control in modern organizations. International Review 3-4: 39-49.

Tarhini, A., El-Masri, M., Ali, M. \& Serrano, A. 2016. Extending the UTAUT model to understand the customers' acceptance and use of internet banking in Lebanon: A structural equation modelling approach. Information Technology and People 29 (4): 20-45. 
Vătămănescu, E., Cegarra-Navarro, J., Andrei, A. G., Dincă, V. \& Alexandru, V. 2020. SMEs strategic networks and innovative performance: A relational design and methodology for knowledge sharing. Journal of Knowledge Management 24(6): 1369-1392.

Voss, U. \& Brette, M. 2014. The effectiveness of management control in small firms: perspectives from resource dependence theory. Journal of Small Business Management 52(3): 569-587.

Wang, Z. \& Wang, N. 2012. Knowledge sharing, innovation and firm performance. Expert Systems with Applications 39(10): 8899-8908.

Warren, J.D, Moffit, K.C. \& Byranes, P. 2015. How big data will change accounting. Business Horizon 29(2): 397-407.

Widener, S. K. 2004. An empirical investigation of the relation between the use of strategic human capital and the design of the management control system. Accounting, Organisations and Society 29(3-4): 377-399.

Xu, L., Wang, C., Luo, X. \& Shi, Z. 2006. Integrating knowledge management and ERP in enterprise information systems. Systems Research and Behavioral Science 23(2): 147-156.

Žabjek, D., Kovačič, A. \& Indihar Štemberger, M. 2009. The influence of business process management and some other CSFs on successful ERP implementation. Business Process Management Journal 15(4): 588-60.

Zaglago, L., Chapman, C. \& Shah, H. 2016. ERP system implementation and tacit knowledge sharing. Proceedings of the World Congress on Engineering 1: 251-256.
Izzeideen A. Alomari

Faculty of Economics and Administrative Sciences Islamic University of Gaza

Gaza

PALESTINE.

E-mail: Iomari@iugaza.edu.ps

Amizawati Mohd Amir*

Faculty of Economics and Management

Universiti Kebangsaan Malaysia

43600 UKM Bangi Selangor

MALAYSIA.

E-mail: amiza@ukm.edu.my

Sofiah Md Auzair

Faculty of Economics and Management

Universiti Kebangsaan Malaysia

43600 UKM Bangi Selangor

MALAYSIA.

E-mail: sofiah@ukm.edu.my

Khairul Azman Aziz

Faculty of Economics and Management

Universiti Kebangsaan Malaysia

43600 UKM Bangi Selangor

MALAYSIA.

E-mail: khairul.aziz@ukm.edu.my

*Corresponding author 